\title{
Nanocrystalline cathode functional layer for SOFC
}

\author{
Aleksander Chrzan ${ }^{1 *}$, Jakub Karczewski ${ }^{2}$, Dagmara Szymczewska ${ }^{1}$, Piotr Jasinski ${ }^{1}$
}

\begin{abstract}
Recently, it was shown that thin functional layers introduced between an electrolyte and cathode might improve cathode performance. However, the mechanism of this improvement still needs analysis. In this paper, a thin $(\sim 140 \mathrm{~nm})$, spin-coated perovskite layer $\left(\mathrm{La}_{0.6} \mathrm{Sr}_{0.4} \mathrm{Co}_{0.2} \mathrm{Fe}_{0.8} \mathrm{O}_{3-\delta}\right)$ was placed between a cathode $\left(\mathrm{La}_{0.6} \mathrm{Sr}_{0.4} \mathrm{Co}_{0.2} \mathrm{Fe}_{0.8} \mathrm{O}_{3-\delta}\right)$ and an electrolyte $\left(\mathrm{Ce}_{0.8} \mathrm{Gd}_{0.2} \mathrm{O}_{2-\delta}\right)$ and the effects of this investigated. The microstructure of this layer was varied in order to determine its impact on the electrical and electrochemical properties. It has been shown that a mesoporous, nanocrystalline layer increases the active area for oxygen reduction and charge transfer through the cathode/electrolyte interface, which improves performance. Moreover, the stability of the cathode from thermal stresses is increased. In contrast, the coarsening of the grain and the layer densification has a reduced impact on the cathode performance.
\end{abstract}

\section{Introduction}

For several years, Solid Oxide Fuel Cells (SOFC) have been widely studied as a very efficient source of electrical energy. Despite many obvious advantages, widespread commercialization of this technology has been significantly limited by high costs. One way to reduce the price is to decrease the operating temperature of the cell, in order to allow the use of less expensive materials [1]. Unfortunately, lowering of the operating temperature is associated with a decrease in ionic conductivity and with a reduction in catalytic activity of both electrodes. To maintain the efficiency of 
the fuel cell, the objective should be to reduce the polarization resistance of the electrodes, as well as the electrolyte ohmic resistance. Processing of the cathode has shown to have an especially strong impact on the polarization resistance [2, 3]. Cathode parameters such as composition, thickness, and microstructure have proven to strongly affect electrochemical performance of SOFC [4].

The $\mathrm{La}_{\mathrm{x}} \mathrm{Sr}_{1-\mathrm{x}} \mathrm{Co}_{\mathrm{y}} \mathrm{Fe}_{1-\mathrm{y}} \mathrm{O}_{3-\delta}(\mathrm{LSCF})$ cathodes family has attracted much attention for intermediate temperature SOFCs because it has both high electronic and oxygen ion conductivity, and also high activity towards oxygen reduction at temperatures as low as $600{ }^{\circ} \mathrm{C}$ [5]. Additionally, the oxygen reduction reaction on the LSCF cathode is limited by the surface exchange process rather than the bulk charge transport process [6]. It also shows good compatibility with YSZ electrolytes if doped ceria is used as a buffer layer between an YSZ and the LSCF cathode [7]. Apart from the bulk properties of the cathode material, the microstructure may also have a significant impact on the operation of the cathode, in particular the cathode-electrolyte interface. Early studies carried out in the mid-90s by Van Herle et al [8] have shown that a cathode in the form of a two-layered structure with an inner thin dense layer covered by an outer thick porous cathode is advantageous from the standpoint of the operation of the fuel cell. Subsequent studies carried out by Hildenbrand et al [9] and Dumaisnil et al [10] consistently confirmed that the use of thin $(200-400 \mathrm{~nm})$ and dense cathode functional layers leads to a reduction in the polarization resistance of the cell, when using a mixed conducting cathode.

Our previous study has shown that the optimum thickness of the functional layer should be around 120-150 nm for both symmetrical cells [11] and fuel cells [12]. The improvement in polarization resistance was obtained by using an electrode with dominating electronic conductivity $\left(\mathrm{LaNi}_{0.6} \mathrm{Fe}_{0.4} \mathrm{O}_{3-\delta}, \mathrm{LNF}\right)$ and for the cathode with mixed conducting LSCF as a thin cathode layer. However, it was pointed out that while the thin functional layer is initially dense and nanocrystalline, it becomes porous due to grain growth during the cathode sintering step. The fact that the final thin layer structure is different from that which was assumed, and strongly depends on the cathode sintering temperature, has not been addressed in previous articles on the subject. The focus of this study is the investigation of the influence of grain size and structure of the cathode thin functional layer on the cathode-electrolyte interface performance. The structure and electrical properties of 
LSCF functional layers prepared at different temperatures were measured. Moreover, the influence of the thin layer on the cathodes stability during thermal stress was investigated for the first time. The LSCF layer was applied on a $\mathrm{Ce}_{0.8} \mathrm{Gd}_{0.2} \mathrm{O}_{2-\delta}(\mathrm{CGO})$ substrate to illustrate a typical arrangement in which the LSCF cathode is applied onto a CGO buffer layer deposited onto an yttria stabilized zirconia electrolyte. The thin LSCF layers were fabricated by spin coating a metallo-organic precursor. This method allowed the microstructure of the required layers to be easily varied by controlling the annealing temperature and deposition parameters.

\section{Experimental}

Two types of samples were used in the experiment. The first was a CGO substrate with a single thin $\mathrm{La}_{0.6} \mathrm{Sr}_{0.4} \mathrm{Co}_{0.2} \mathrm{Fe}_{0.8} \mathrm{O}_{3}$ (LSCF) layer for DC measurements and SEM analysis. The second type used was a symmetrical cell with a dense thin LSCF layer on both sides of a CGO electrolyte covered with porous LSCF cathode, along with a silver current collector (see Fig. 1). This second setup was used for impedance analysis.

CGO pellets with a diameter of $13 \mathrm{~mm}$ were prepared from the CGO powder (GDC-20K, Daiichi Kigenso Kagaku Kogyo), which was uniaxially pressed under a pressure of $100 \mathrm{MPa}$ and sintered at $1350{ }^{\circ} \mathrm{C}$ for 4 hours. Their density was measured using a fluid displacement method as $99 \%$ of the theoretical. Afterwards their surface was grinded to a thickness of approximately $0.9 \mathrm{~mm}$ and polished. The thin layer precursor was prepared using a modified Pechini method [13]. Lanthanum, strontium, cobalt and iron nitrates were dissolved in distilled water with citric acid and mixed with ethylene glycol (all reagents by Sigma-Aldrich). After evaporation of the distilled water (on a hot plate), the precursor was diluted with 2-ethoxyethanol, which decreased the viscosity and increased the wetting properties. Thin layers were deposited by spin coating for 2 minutes at $4000 \mathrm{rpm}$. After each deposition, the samples were dried at $500{ }^{\circ} \mathrm{C}$ on a hot plate. In this state, the organic components of the precursor had mostly decomposed and evaporated. Five depositions were needed in order to obtain a thickness of $140 \mathrm{~nm}$. For the symmetrical cells, this procedure was repeated on the other side of the CGO. After the deposition process, the CGO substrates with thin layers were annealed at temperatures ranging from $500{ }^{\circ} \mathrm{C}$ to $1200{ }^{\circ} \mathrm{C}$ for 1 hour. The sides of the pellets were ground down to remove 
excess LSCF. A LSCF paste (4421-A, ESL Europe) was brush painted three times on each side yielding a flat, approximately $60 \mu \mathrm{m}$ thick, porous electrode. After it had dried, a single layer of an $\mathrm{Ag} / \mathrm{YSZ}$ paste was brush painted forming porous a current collector layer. Then the structure was sintered at $800{ }^{\circ} \mathrm{C}$ for 1 hour. The samples for DC measurements and SEM analysis were coated with LSCF on one side of the CGO and annealed without deposition of any additional layers.

The High Temperature X-Ray Diffraction (HT-XRD) of the LSCF precursor dried at $400{ }^{\circ} \mathrm{C}$ and mixed with CGO powder was used to determine the crystallization process, structure and crystalline size. A Bruker D8 diffractometer with MRI high temperature stage and PSD Lynx Eye detector using $\mathrm{CuK} \alpha(1.542 \AA)$ radiation was applied within a temperature range of 500 to $1000{ }^{\circ} \mathrm{C}$ with holding time of 80 minutes at each measurements temperature. The morphology of the samples was analyzed using a FEI Quanta FEG 250 Scanning Electron Microscope (SEM) operating with a secondary electron detector in a high vacuum mode with an accelerating voltage of $10 \mathrm{kV}$. A layer of gold was deposited on the samples prior to SEM examination. DC conductivity of thin LSCF layers was measured using the van der Pauw method for samples with thin layers deposited onto the CGO substrate. Point contacts were prepared on the circumference of the sample with silver paste (4922N, Du Pont). Since CGO becomes conductive at high temperatures, the measurements were performed at temperatures ranging from 150 to $600{ }^{\circ} \mathrm{C}$ (except for the samples annealed at 500 and $600{ }^{\circ} \mathrm{C}$ ) and CGO conductivity was taken into account to calculate the LSCF thin layer conductivity. Electrochemical impedance spectroscopy of the symmetrical cells was performed in dry air using Novocontrol AlphaA in the temperature range of 500 to $800{ }^{\circ} \mathrm{C}$, with a frequency range of $100 \mathrm{mHz}$ to $1 \mathrm{MHz}$ and an amplitude of $20 \mathrm{mV}$. Two symmetrical samples with the layer annealed at $700{ }^{\circ} \mathrm{C}$ and a reference without the layer were chosen for stability tests. These were repeatedly heated-up to $700{ }^{\circ} \mathrm{C}$ and then cooled-down to $100{ }^{\circ} \mathrm{C}$ to accelerate cathode/electrolyte interface degradation due to a thermal expansion coefficient mismatch. Each time the sample was stabilized at $700{ }^{\circ} \mathrm{C}$, a impedance measurement was performed. 
Selected measurements were compared using ADIS analysis [14]. This was performed by subtracting

the derivative of the real part of the impedance $Z_{\text {SAMPLE }}$ ' with respect to the natural logarithm of the frequency of the sample from the similar derivative of the reference $Z_{\text {REFERENCE }}$, which is written as:

$$
A D I S=\frac{\partial Z^{\prime}{ }_{S A M P L E}(\omega)}{\partial \ln (\omega)}-\frac{\partial Z^{\prime}{ }_{R E F E R E N C E}(\omega)}{\partial \ln (\omega)}
$$

This method enables easy visual comparison between different spectra as a function of frequency. For this reason, it can be used to better understand the nature of the differences between the electrochemical responses of cathodes with altered microstructure [15]. Moreover, ADIS analysis is particularly useful when small changes in behaviour of single sample occur, e.g. when working conditions slowly change or the sample degrades [16]. It is worth noting that derivative of $Z$ ' is negative thus positive $A D I S$ values should be interpreted as lowered impedance of the sample in respect to the reference.

\section{Results and discussion}

The precursor used for cathode thin layer preparation after drying at a temperature of $500{ }^{\circ} \mathrm{C}$ has an amorphous structure. In order to investigate the crystallization temperature, pure LSCF precursor and LSCF precursor mixed with CGO powder were examined using HT-XRD. In Figure 2A XRD spectra at $550{ }^{\circ} \mathrm{C}$ (lower plot) and at $600{ }^{\circ} \mathrm{C}$ (upper plot) of LSCF mixed with CGO powder are shown. At $550{ }^{\circ} \mathrm{C}$ only maxima originating from the $\mathrm{CGO}$ phase and a Pt holder are visible, while at $600{ }^{\circ} \mathrm{C}$ peaks from the perovskite LSCF phase can be observed. Thus, between $550^{\circ}$ and $600{ }^{\circ} \mathrm{C} \mathrm{LSCF}$ crystallization occurs. To present the crystallization process clearly, Figure $2 \mathrm{~B}$ shows the main peak of the LSCF phase $\left(2 \Theta \approx 31.7^{\circ}\right)$ measured at increasing temperatures. The presence of the perovskite phase can be observed beginning at a temperature of $600{ }^{\circ} \mathrm{C}$. Further increases of temperature lead to a change in the peak shape (narrowing) due to the increased size of the grains. Moreover, the shifting of the peak occurs as a result of the lattice thermal expansion [17]. Figures 3A-C present the surfaces of $140 \mathrm{~nm}$ thick cathode layers annealed at $800{ }^{\circ} \mathrm{C}, 1000{ }^{\circ} \mathrm{C}$, and $1200{ }^{\circ} \mathrm{C}$, respectively. One can see that this results in an increase of the grain size from $50 \mathrm{~nm}$ for the annealing temperature of $800{ }^{\circ} \mathrm{C}$, 
through $150 \mathrm{~nm}$ for $1000{ }^{\circ} \mathrm{C}$, to $300 \mathrm{~nm}$ for $1200{ }^{\circ} \mathrm{C}$. The roughness of the continuous layers visible in

Figures 3A and B reflects the shape of CGO substrate grains. The cumulative result of the thin layer grain size measurements, obtained by both Scherrer analysis of the XRD peaks broadening and analysis of the SEM images is shown in Figure 4. It can be seen that the annealing temperature of $900{ }^{\circ} \mathrm{C}-1000{ }^{\circ} \mathrm{C}$ leads to the formation of the a layer at which the particle size equals the thickness of the applied layer. At temperatures higher than $1000^{\circ} \mathrm{C}$, a change in the thin layer coverage of the electrolyte substrate can be seen. The growth of particles over the size of $140 \mathrm{~nm}$, thus over the layer thickness, leads to inhomogeneities, discontinuities and, in an extreme case (annealing at $1200{ }^{\circ} \mathrm{C}$ ), to the formation of isolated islands, as seen in Figure 3C. This phenomenon was also observed for YSZ sol-gel films in [18]. In the case of the smaller grains, layers uniformly cover the surface of the electrolyte. A dense layer annealed at $800{ }^{\circ} \mathrm{C}$ has a thickness of approximately $140 \mathrm{~nm}$, which corresponds at this temperature to a size of three grains. The cross-section of the sample prepared under these conditions is shown in Figure 3D. Well-established contact with the surface of the electrolyte is visible. Furthermore, small pores between 10-30 nm are observed in the layer annealed at $800{ }^{\circ} \mathrm{C}$ (with a grain size of approximately $50 \mathrm{~nm}$ ). Pores of this size may be classified as mesoporosity [19]. These mesopores are more visible in the SEM micrographs shown in Figure 5. Figure 5A presents the surface of the layer with pinholes. In the cross-section presented in Figure 5B, potentially percolating pores can be seen. This suggests that the layer annealed at $800{ }^{\circ} \mathrm{C}$ may be neither perfectly dense, nor gas-tight.

As described above, the structure of the cathode functional layer is significantly affected by the method of its preparation. Further studies were carried out to ascertain the influence of the microstructure of the cathode functional layer on its electrical and electrochemical properties. Namely, DC electrical conductivity studies of thin films were performed. Figure 6A shows the electrical conductivity of the layers plotted as a function of annealing temperature. Figure $6 \mathrm{~B}$ shows the electrical conductivity measured at $500{ }^{\circ} \mathrm{C}$ for the different annealing temperatures. It is visible that the initial increase of the annealing temperature from $500{ }^{\circ} \mathrm{C}$ to $800{ }^{\circ} \mathrm{C}$ and the related increase of the grain size, leads to an increase in the electrical conductivity. The highest conductivity was obtained for 
the annealing at $800{ }^{\circ} \mathrm{C}$, namely $106 \mathrm{~S} \mathrm{~cm}^{-1}$ at $600{ }^{\circ} \mathrm{C}$. For this layer the size of the grains is still three times smaller than the thickness of the layer. At higher annealing temperatures, a linear decrease in conductivity is observed, most likely, associated with the lower effective grain-to-grain connection due to grain spheroidization once the grain size becomes comparable with the layer thickness. For the sample annealed at $1100{ }^{\circ} \mathrm{C}$ (and above), at which the formation of isolated islands was observed, the electrical conductivity is not measurable. The highest measured conductivity of $106 \mathrm{~S} \mathrm{~cm}^{-1}$ is about third the value reported by Tai [17] for bulk sample, namely $330 \mathrm{~S} \mathrm{~cm}^{-1}$.

The electrochemical studies performed on the symmetrical cells with porous cathodes using impedance spectroscopy allowed the determination of the area specific resistance $(A S R)$. ASR values obtained were no higher than 960,122 and $36 \mathrm{~m} \Omega \mathrm{cm}^{2}$ at 600,700 and $800{ }^{\circ} \mathrm{C}$, respectively. Figure 7 shows the Nyquist plots at $700{ }^{\circ} \mathrm{C}$ (with series resistance subtracted) of the most distinctive symmetrical samples, namely without a LSCF layer (a reference) and with a thin LSCF layer annealed at $700{ }^{\circ} \mathrm{C}, 1000{ }^{\circ} \mathrm{C}$ and $1200{ }^{\circ} \mathrm{C}$. Points denote experimental data, while solid lines are calculated fits of the equivalent circuits. The equivalent circuit consisted of three parallel $\mathrm{R}-\mathrm{CPE}$ (constant phase element) elements, which represent three spectrum features recognizable at $700{ }^{\circ} \mathrm{C}$. The equivalent circuit is shown in Figure 7. At the measurement temperature of $700{ }^{\circ} \mathrm{C}$, the series resistance mostly originates from both bulk and grain boundary CGO conductivity, since their characteristic frequencies are above the measurable spectrum [20]. The CGO properties are not investigated in this paper, thus the series resistance is omitted. High (R1-CPE1) and middle (R2-CPE2) frequency features are the result of electrode reaction, most likely the higher frequency signal is related to surface oxygen exchange, while the lower frequency is a result of cathode/electrolyte interfacial resistance [21]. However, these two features have similar characteristic frequencies and for most of the cases, it is impossible to correctly distinguish each contribution. At $700{ }^{\circ} \mathrm{C}$ and above, R3-CPE3 becomes visible within the low frequency range, i.e. below $10 \mathrm{~Hz}$. It is usually associated with limited gas diffusion through an electrode [9]. At $700{ }^{\circ} \mathrm{C} \mathrm{ASR}_{3}$ values were in the range of $4-15 \mathrm{~m} \Omega \mathrm{cm}^{2}$. It is visible that the layer annealed at $700{ }^{\circ} \mathrm{C}$ affected the impedance spectrum in comparison to the reference sample. All three resistances decreased, while the capacitances of the electrode reactions increased. As a result, 
the characteristic frequencies of processes 1 and 2 were lowered from $83.0 \mathrm{kHz}$ to $0.9 \mathrm{kHz}$ and from to exhibit a significant difference during the third, diffusive process, as its resistance decreased. In addition, processes shifting resulted in the overlapping of features 2 and 3. It may be explained, that the thin cathode layer increases the surface over which charge transfer between the cathode and electrolyte occurs, which enables more oxygen ions to diffuse through the bulk of the LSCF. Furthermore, the surface exchange on the thin layer may additionally occur due to its mesoporous nature. This directly leads to smaller resistance and larger capacitance of these processes. On the other hand, in the case of the layer annealed at $1000{ }^{\circ} \mathrm{C}$ the increase in ASR occurs, namely from 103 to 122 $\mathrm{m} \Omega \mathrm{cm}^{2}$, compared to the reference. This diminished performance may be explained by the fact that the layer annealed at $1000{ }^{\circ} \mathrm{C}$ has grains of a similar size to the actual layer thickness, forming a thin film which is both coarser and denser. In this case, the surface area for oxygen reduction is decreased and the length of the triple phase boundary is lowered, because the electrolyte is separated from the molecular oxygen. When the layer was annealed at $1200{ }^{\circ} \mathrm{C}$ and its grains were completely separated from each other, the impedance spectrum of the cathode became similar to the reference. Small deviations may be a result of inter-diffusion between the LSCF and CGO, which can occur at $1200{ }^{\circ} \mathrm{C}$ $[22,23]$ or slightly altered sintering of the cathode/electrolyte interface, which can improve cathode preparation repeatability [11].

Figure 8 shows the ADIS plots of the impedance spectra shown in Figure 7, calculated in relation to the reference sample (without the LSCF thin layer). It is visible that the differential of the real part of impedance at frequencies above $1 \mathrm{kHz}$ shows improvement over the reference and is almost identical for two samples, namely, those with layers annealed at 700 and $1000{ }^{\circ} \mathrm{C}$. However, at frequencies below $1 \mathrm{kHz}$ the sample annealed at higher temperature shows significant deterioration of the impedance. The sample with a layer annealed at $1200{ }^{\circ} \mathrm{C}$ became similar to the reference except for increased capacitance of electrode processes (the decrease in the ASR was not significant). As a result, characteristic frequencies shifted slightly towards lower values. At the lower frequencies $(<10 \mathrm{~Hz})$ 
related to diffusion processes, the impedances are very similar and as a result the ADIS values are relatively low.

In Figure 9, the symmetrical cell polarization resistance measurements carried at $700{ }^{\circ} \mathrm{C}$ for thin LSCF layers annealed at different temperatures are presented. The reference sample without thin layer showed an $A S R$ value of $103 \mathrm{~m} \Omega \mathrm{cm}^{2}$. The lowest and very similar polarization resistances were obtained for the annealing temperatures at and below $700{ }^{\circ} \mathrm{C}\left(\sim 60 \mathrm{~m} \Omega \mathrm{cm}^{2}\right)$. This suggests that the annealing of the layers far below the cathodes sintering temperature does not have much influence on the obtained results. The final microstructure and properties of the cathode functional layer, in these cases, will be developed during the porous cathode sintering step and operation of the cell. However, it is worth noticing that the cell with the layer annealed at $800{ }^{\circ} \mathrm{C}$ showed a higher $A S R$ value $\left(78 \mathrm{~m} \Omega \mathrm{cm}^{2}\right)$ than the layer annealed at $700{ }^{\circ} \mathrm{C}\left(60 \mathrm{~m} \Omega \mathrm{cm}^{2}\right)$. This may indicate, that the layer annealed at $700{ }^{\circ} \mathrm{C}$ sinters better with the porous cathode, because it still undergoes grain growth at the cathode sintering temperature of $800{ }^{\circ} \mathrm{C}$. A thin layer obtained at low annealing temperatures allows the formation of an improved interface between the electrolyte and cathode enabling effective charge transfer. Moreover, small grains form additional triple phase boundary, as stated previously. Increasing the sintering temperature and the related grain growth, resulted in an increase of polarization resistance. At an annealing temperature of $1000{ }^{\circ} \mathrm{C}$, this value is higher than for the cell without the cathode functional layer, at this temperature polarization resistance reaches its maximum of $122 \mathrm{~m} \Omega \mathrm{cm}^{2}$, as stated before. In this case, the temperature causes the grains to grow to a level comparable with the thickness of the applied layer. This leads to the formation of a solid boundary layer, which limits the effective exchange of oxygen. Further grain growth (at $1100{ }^{\circ} \mathrm{C}$ and more) creates a discontinuous layer, which results in a reduction of polarization resistance. The discontinuous layer no longer meets the role of the functional layer, and the investigated system ceases to differ significantly from the traditional system with a direct interface between the porous cathode and the electrolyte. As noted previously, at this temperature inter-diffusion between CGO and LSCF may occur. 
As presented above, the introduction of the nano-structured cathode functional layer leads to the $40 \%$

decrease in the polarization resistance of the interface between the electrolyte and the cathode.

Improvement in this range is in agreement with previous studies by Hildenbrand [9] and Dumaisnil [10] who reported decrease of ASR at $600{ }^{\circ} \mathrm{C}$ from $0.67 \Omega \mathrm{cm}^{2}$ to $0.21 \Omega \mathrm{cm}^{2}$ and from $0.38 \Omega \mathrm{cm}^{2}$ to $0.26 \Omega \mathrm{cm}^{2}$, respectively. An additional advantage of using the above-described layers is in improved stability of the entire system. In order to enforce faster ageing of the cathode, samples with and without $140 \mathrm{~nm}$ thick thin layers annealed at $700{ }^{\circ} \mathrm{C}$ were periodically heated-to $700{ }^{\circ} \mathrm{C}$ and cooleddown to $100{ }^{\circ} \mathrm{C}$. The measurements taken at $700{ }^{\circ} \mathrm{C}$ showed deterioration of the polarization resistance possibly due to cathode cracking and delamination. Figure 10A presents changes of the cathode ASR both with and without a functional layer during ageing of the samples. A noticeable difference in the level of the initially measured resistance can be seen. Besides this, a systematic increase in the ASR for a typical interface and practically stable operation for a system with cathode functional layer during ageing may be observed. The increase in the $A S R$ value of the reference sample is linear, namely $1.3 \mathrm{~m} \Omega \mathrm{cm}^{2}$ per cycle. On the other hand, both cathodes show deterioration of apparent electrolyte conductivity $\sigma$ (calculated from series resistance), which is shown in Figure 10B. In this case, the conductivity of the sample with the LSCF layer decreases at a the rate of $12 \mu \mathrm{S} \mathrm{cm}^{-1}$ per cycle, which is twice as fast as the sample without the LSCF layer. It is however, only $0.02 \%$ of initial conductivity (60.4 mS cm$~^{-1}$ ), which is $5 \mathrm{mS} \mathrm{cm}^{-1}$ more than the initial conductivity of the reference sample. As a result, the increase in total resistance was significantly larger for the reference sample. Figure 11 shows $A D I S$ analysis of aged samples with respect to the initial measurements. It is visible, that the sample without the layer, suffered from an increase in $Z^{\prime}$ within the range of frequencies between $5 \mathrm{~Hz}$ and $2 \mathrm{kHz}$. The change was visible mainly for the second R-CPE element, for which both ASR and capacitance increased. As a result, the characteristic frequency was reduced from 1.4 to $0.7 \mathrm{kHz}$. This can be attributed to the deterioration of the cathode/electrolyte interface, and thus the charge transfer occurring over a smaller area. On the other hand, in the case of the sample with the LSCF layer, a small decrease in the characteristic frequency of the electrode reaction is visible. It progresses during the ageing, however, the polarization resistance is virtually unaffected. 
There was no visible difference in cathode/electrolyte interface morphology observed before and after the ageing process (SEM micrographs not shown here).

\section{Conclusion}

The study showed that the microstructure of the cathode functional layer with a thickness of $140 \mathrm{~nm}$ has a significant impact on cathode electrochemical performance. It was shown, that this layer should be mesoporous and its desirable grain size should be as small as possible. Such mesoporous and nanocrystalline structure can reduce the polarization resistance of the cathode - electrolyte interface by about $40 \%$ and can improve the stability of cell performance. Spin coating of metallo-organic precursor allows a very fine grain structure to be obtained, however the final size of the crystalline structure is determined by the sintering temperature of the cathode.

\section{Acknowledgments}

This work is partly supported by a project founded by National Science Centre Poland based on decision DEC-2012/05/B/ST7/02153 and Statutory Funds for Research at Gdansk University of Technology. The authors acknowledge the facilities, scientific and technical assistance of Department of Energy Conversion and Storage, Technical University of Denmark in HT-XRD analysis.

\section{References}

1. Zha, Y., XIa, C., Jia, L., Wang, Z., Li, H., Yu, J. \& Li, Y., Recent progress on solid oxide fuel cell: Lowering temperature and utilizing non-hydrogen fuels. International Journal of Hydrogen Energy 38, 16498-16517 (2013).

2. Samson, A., Søgaard, M., Knibbe, R. \& Bonanos, C., High performance cathodes for Solid Oxide Fuel Cells prepared by infiltration of La0.6Sr0.4CoO3-d into Gd-doped ceria. Journal of Electrochemical Society 158, B650-B659 (2011).

3. Irvin, J. T. S., Neagu, D., Verbraeken, M. C., Chatzichristodoulou, C., Graves, C. R. \& Mogensen, 
M. B., Evolution of the electrochemical interface in high-temperature fuel cells and electrolysers. Nature Energy 1, 15014 (2016).

4. Skinner, S. J., Recent advantages in perovskite-type materials fo SOFC cathodes. Fuel Cells Bulletin 33, 6-12 (2001).

5. Beckel, D., Muecke, U. P., Gyger, T., Florey, G., Infortuna, A. \& Gauckler, L. J., Electrochemical performance of LSCF based thin film cathodes prepared by spray pyrolysis. Solid State Ionics $\mathbf{3 3}$, 6-12 (2001).

6. Lane, J. A., Benson, S. J., Waller, D. \& Kilner, J. A., Oxygen trasnport in Las0.6Sr0.4Co0.2Fe0.8O3-d. Solid State Ionics 121, 201-208 (1999).

7. Liu, Z., Liu, M., Nie, L. \& Liu, M., Fabrication and characterization of functionally-graded LSCF cathodes by tape casting. International Journal of Hydrogen Energy 38 (2), 1082-1087 (2013).

8. Van Herle, J., McEvoy, A. J. \& Ravindranathan Thampi, K., Oxygen Reduction at Porous and Dense Cathodes for Solid Oxide Fuel Cells. Electrochimica Acta 39 (11/12), 1675-1680 (1994).

9. Hildenbrand, N., Boukamp, B. A., Nammensma, P. \& Blank, D. H. A., Improved cathode/electrolyte interface of SOFC. Solid State Ionics 192, 12-15 (2011).

10. Dumaisnil, K., Fasquelle, D., Mascot, M., Rolle, A., Roussel, P. \& Minaud, S., Synthesis and characterization of $\mathrm{La} 0.6 \mathrm{Sr} 0.4 \mathrm{Co} 0.8 \mathrm{Fe} 0.2 \mathrm{O} 3$ films for solid oxide fuel cells. Thin Solid Films 553, 89-92 (2014).

11. Chrzan, A., Karczewski, J., Gazda, M., Szymczewska, D. \& Jasinski, P., Investigation of thin perovskite layers between cathode and doped ceria used as buffer layer in solid oxide fuel cells. Journal Solid State Electrochemistry (9), 1807-1815 (2015).

12. Molin, S., Chrzan, A., Karczewski, J., Szymczewska, D. \& Jasinski, P., THE ROLE OF THIN 
FUNCTIONAL LAYER IN SOLID OXIDE FUEL CELLS. Electrochimica Acta 204, 136-145 (2016).

13. Jasinski, P., Molin, S., Gazda, M., Petrovski, V. \& Anderson, H. U., Application of spin coating of polymer precursor and slurry suspensions for Solid Oxide Fuel Cell fabrication. Journal of Power Sources 194, 10-15 (2009).

14. Jensen, S. H., Hauch, A., Hendriksen, P. V., Mogensen, M., Bonanos, N. \& Jacobsen, T., A Method to Separate Process Contributions in Impedance Spectra by Varation of Test Conditions. Journal of Electrochemical Society 154 (12), B1325-B1330 (2007).

15. Klemens $\varnothing$, T., Nielsen, J., Blennow, P., Persson, Å. H., Stegk, T., Christensen, B. H. \& Sønderby, S., High performance metal-supported solid oxide fuel cells with Gd-doped ceria barrier layers. Journal of Power Sources 196 (22), 9459-9466 (2011).

16. Lust, E., Küngas, R., Kivi, I., Kurig, H., Möller, P., Anderson, E., Lust, K., Tamm, K., Samussenko, A. \& Nurk, G., Electrochemical and gas phase parameters of cathodes for intermediate temperature solid oxide fuel cells. Electrochimica Acta 55 (26), 7669-7678 (2010).

17. Tai, L.-W., Nasrallah, M. M., Anderson, H. U., Sparlin, D. M. \& Sehlin, S. R., Structure and electrical properties of La1-xSrxCo1-yFeyO3. Part 2. The system La1-xSrxCo0.2Fe0.8O3. Solid State Ionics 76, 273-283 (1995).

18. Díaz-Parralejo, A., Ortiz, A. L. \& Caruso, R., Effect of sintering temperature on the microstructure and mechanical properties of $\mathrm{ZrO} 2-3$ mol\%Y2O3 sol-gel films. Ceramics International 36, 2281$2286(2010)$.

19. Rouquerol, J., Anvir, D., W., F. C., Everett, D. H., Haynes, J. M., Pernicone, N., F., R. J. D., Sing, K. S. W. \& Unger, K. K., Recommendations for the characterization of porous solids (Technical Report). Pure and Applied Chemistry 66 (8), 1739-1758 (1994). 
20. Pérez-Coll, D., Marrero-López, D., Núñez, P., Piñol, S. \& Frade, J. R., Grain boundary conductivity of $\mathrm{Ce} 0.8 \mathrm{Ln} 0.2 \mathrm{O} 2-\delta$ ceramics $(\mathrm{Ln}=\mathrm{Y}, \mathrm{La}, \mathrm{Gd}, \mathrm{Sm})$ with and without Co-doping. Electrochimica Acta 51 (28), 6463-6469 (2006).

21. Baumann, F. S., Fleig, J., Habermeier, H.-U. \& Maier, J., Impedance spectroscopic study on welldefined (La,Sr)(Co,Fe)O3-d model electrodes. Solid State Ionics 177, 1071-1081 (2006).

22. Izuki, M., Brito, M. E., Yamaji, K., Kishimoto, H., Cho, D.-H., Shimonosono, T., Horita, T. \& Yokokawa, H., Interfacial stability and cation diffusion across the LSCF/GDC interface. Journal of Power Sources 196, $7232-7236$ (2011).

23. Kiebach, R., Zhang, W.-W., Zhang, W., Chen, M., Norrman, K., Wang, H.-J., Bowen, J. R., Barfod, R. \& Hendriksen, P. V., Stability of La0.6Sr0.4Co0.2Fe0.8O3/Ce0.9Gd0.1O2 cathodes during sintering and aolid oxide fuel cell operation. Journal of Power Sources 283, 151-161 (2015).

\section{Figure captions}

Fig.1 Schematic representation of the symmetrical cell.

Fig.2 A) HT-XRD patterns of the LSCF precursor mixed with CGO powder obtained at $550{ }^{\circ} \mathrm{C}$ and at $600^{\circ} \mathrm{C}, \mathrm{B}$ ) main peak of LSCF perovskite phase during heating to $1000^{\circ} \mathrm{C}$.

Fig.3 SEM micrographs of the $140 \mathrm{~nm}$ LSCF thin layer deposited on CGO substrate. A-C) Surfaces of the layer annealed at $800{ }^{\circ} \mathrm{C}, 1000{ }^{\circ} \mathrm{C}, 1200{ }^{\circ} \mathrm{C}$, respectively. D) Cross-section of the sample with thin layer annealed at $800{ }^{\circ} \mathrm{C}$ and sintered with porous cathode, I - porous cathode, II -thin layer, III CGO substrate..

Fig.4 Grain size of LSCF layer as a function of annealing temperature, measured by Scherrer analysis of the XRD peaks broadening and analysis of the SEM images. 
Fig.5 SEM micrographs of the $140 \mathrm{~nm}$ LSCF thin layer annealed at $800{ }^{\circ} \mathrm{C}$ with visible mesoporosity. A) Surface scan, B) cross-section.

Fig.6 A) Temperature dependence of the DC electrical conductivity of the layers annealed at different temperatures. B) Sintering temperature dependence of the DC electrical conductivity, measured at $500{ }^{\circ} \mathrm{C}$.

Fig.7 Equivalent circuit and Nyquist plots for symmetrical samples with and without a thin LSCF layer annealed at 700,1000 and $1200{ }^{\circ} \mathrm{C}$. Measurements performed at $700{ }^{\circ} \mathrm{C}$. Solid lines denote equivalent fits. Numbers over the empty symbols indicate logarithm of the frequency.

Fig.8 ADIS plots of samples with the LSCF layer annealed at selected temperatures in relation to reference without the LSCF layer.

Fig.9 Area specific resistance of symmetrical cells measured at $700{ }^{\circ} \mathrm{C}$ as a function of thin layer annealing temperature.

Fig.10 Relative change of A) the area specific resistance of the symmetrical cell, B) electrolyte apparent conductivity as a function of number of heating/cooling cycles.

Fig.11 ADIS plots of samples during the ageing with respect to their first measurement for A) sample without the thin layer, B) sample with the layer. 


\section{$\mathrm{Ag} / \mathrm{YSZ}$ current collector LSCF cathode} CGO

LSCF cathode $\mathrm{Ag} / \mathrm{YSZ}$ current collector
LSCF thin layer annealed at different temperatures

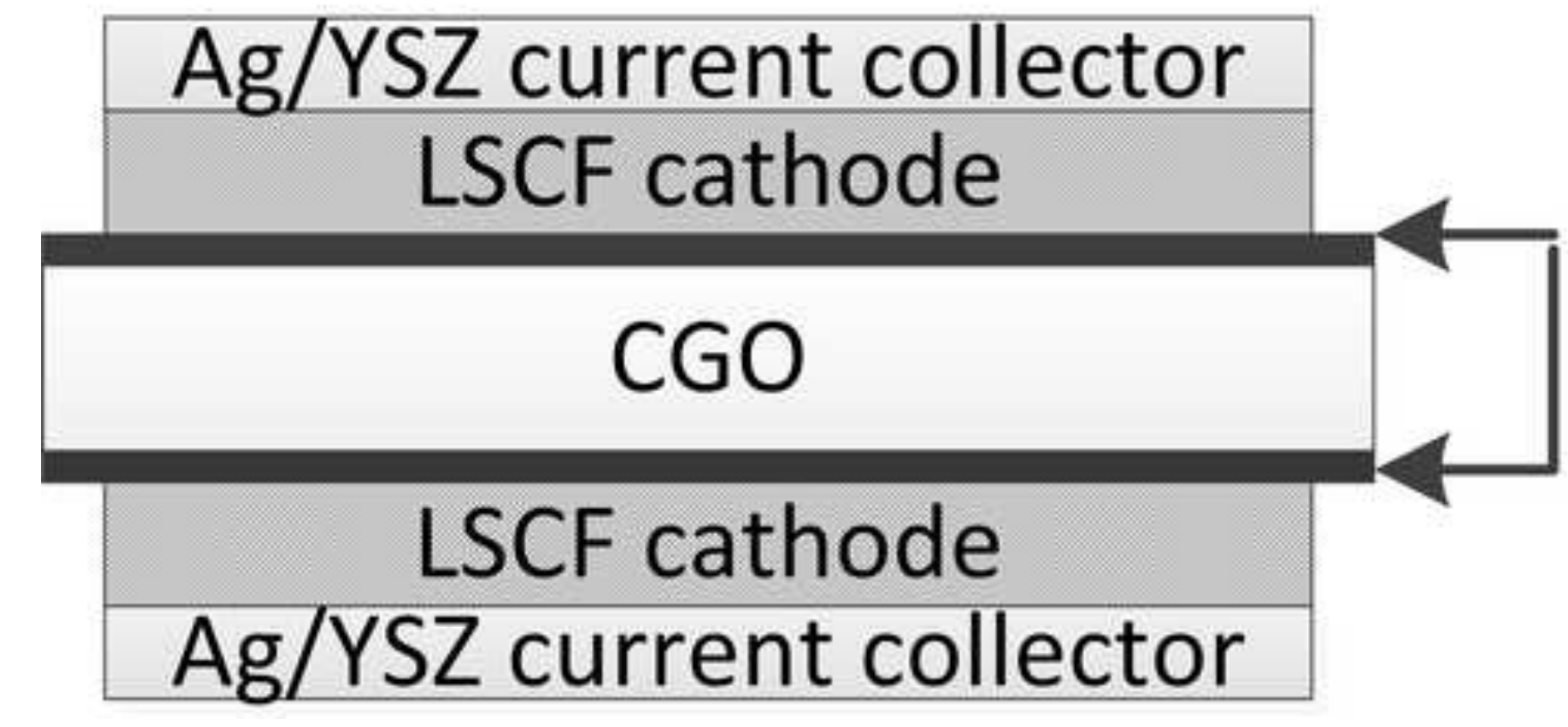



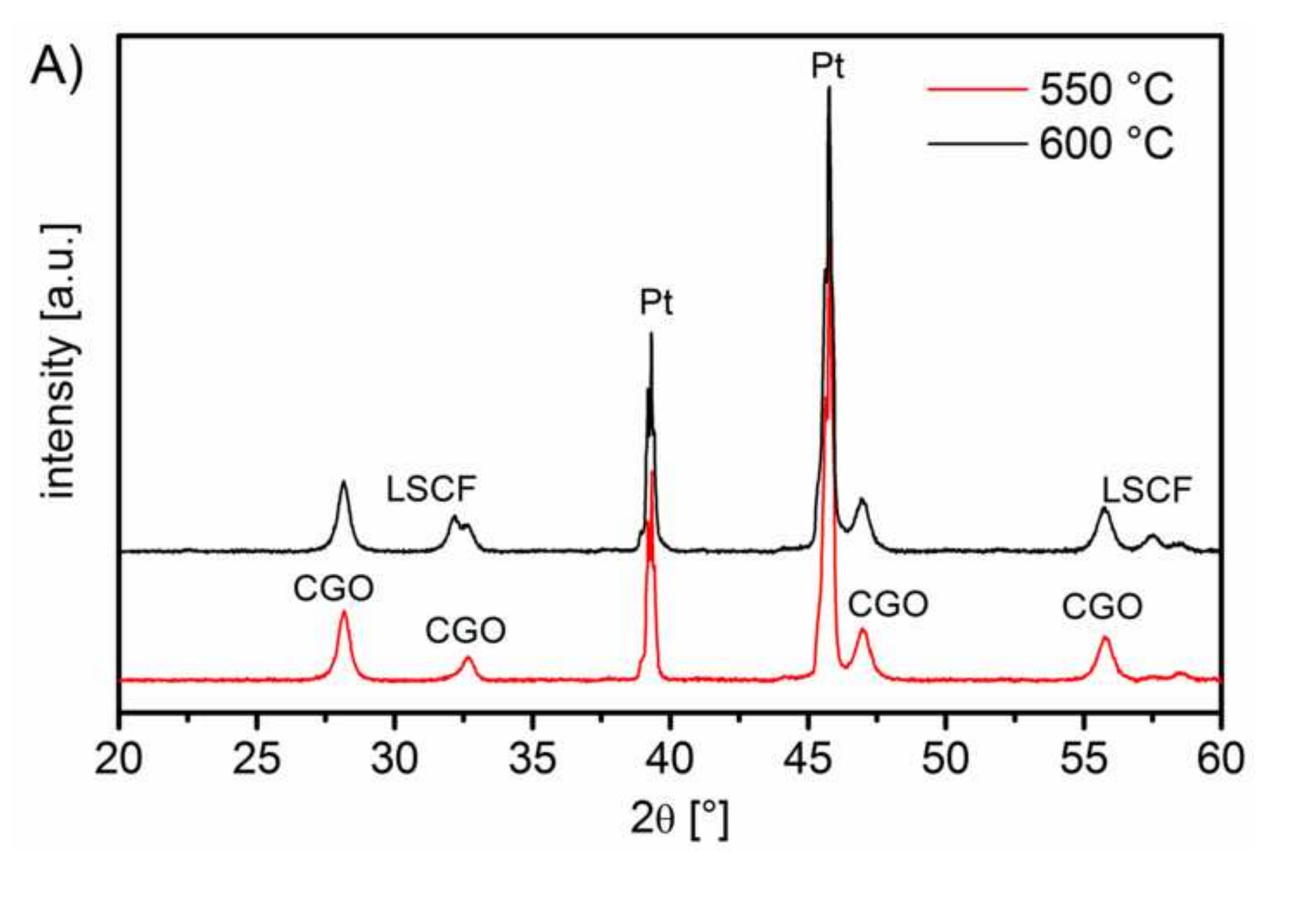

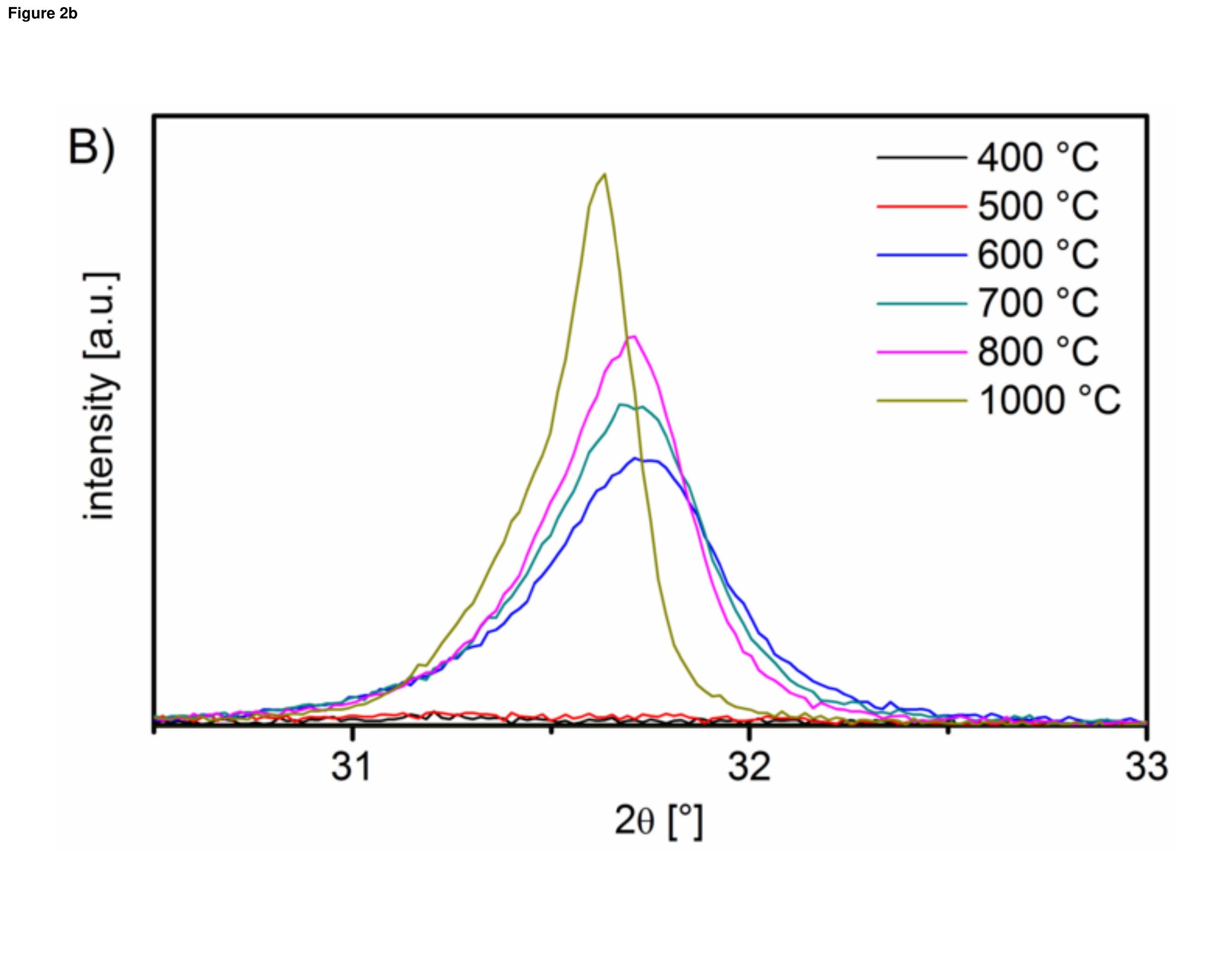

(⿸丆口
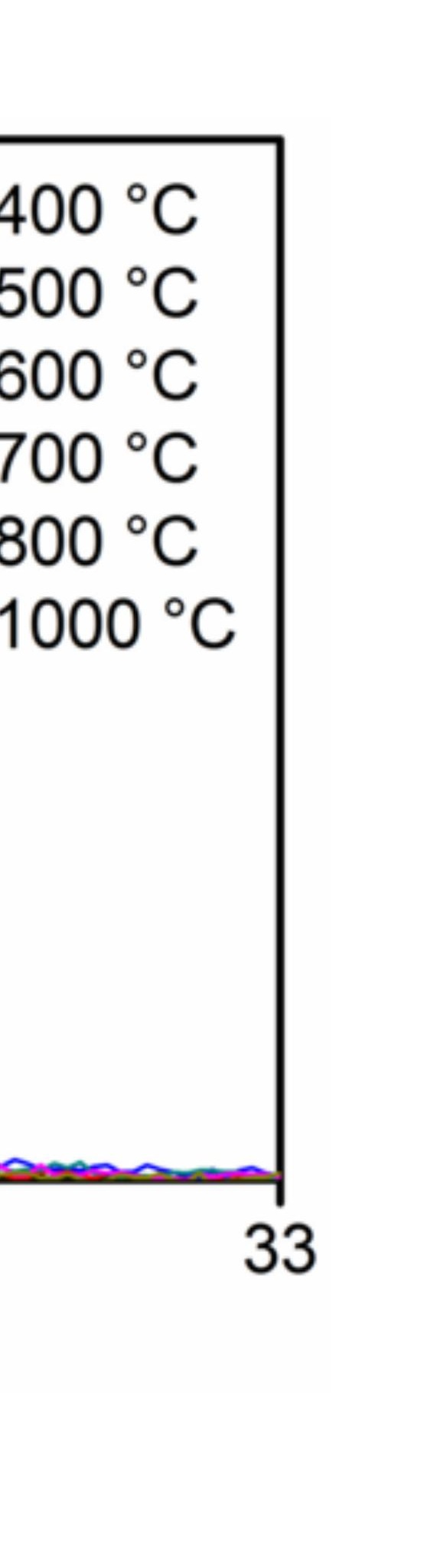


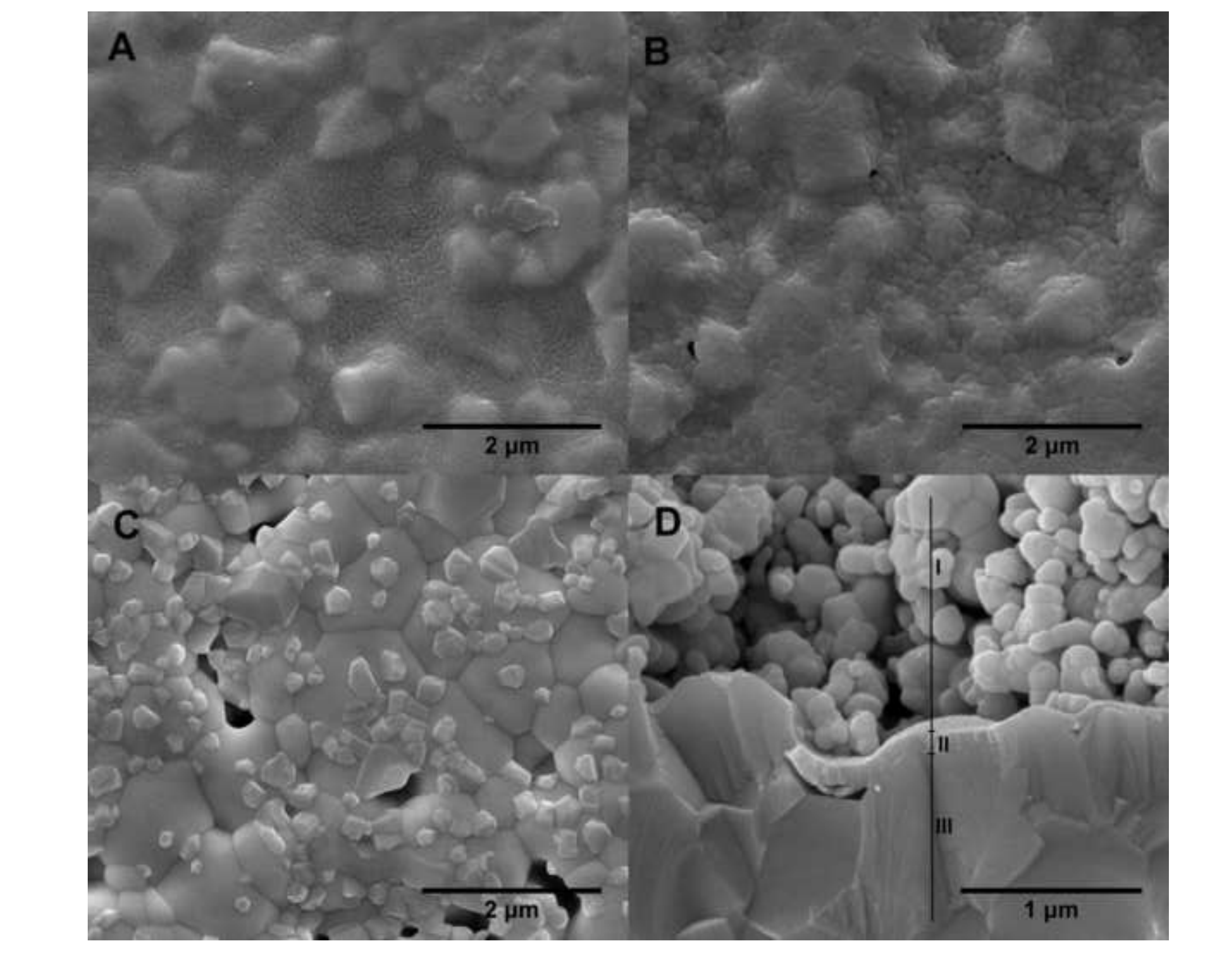$$
\text { . }
$$ 


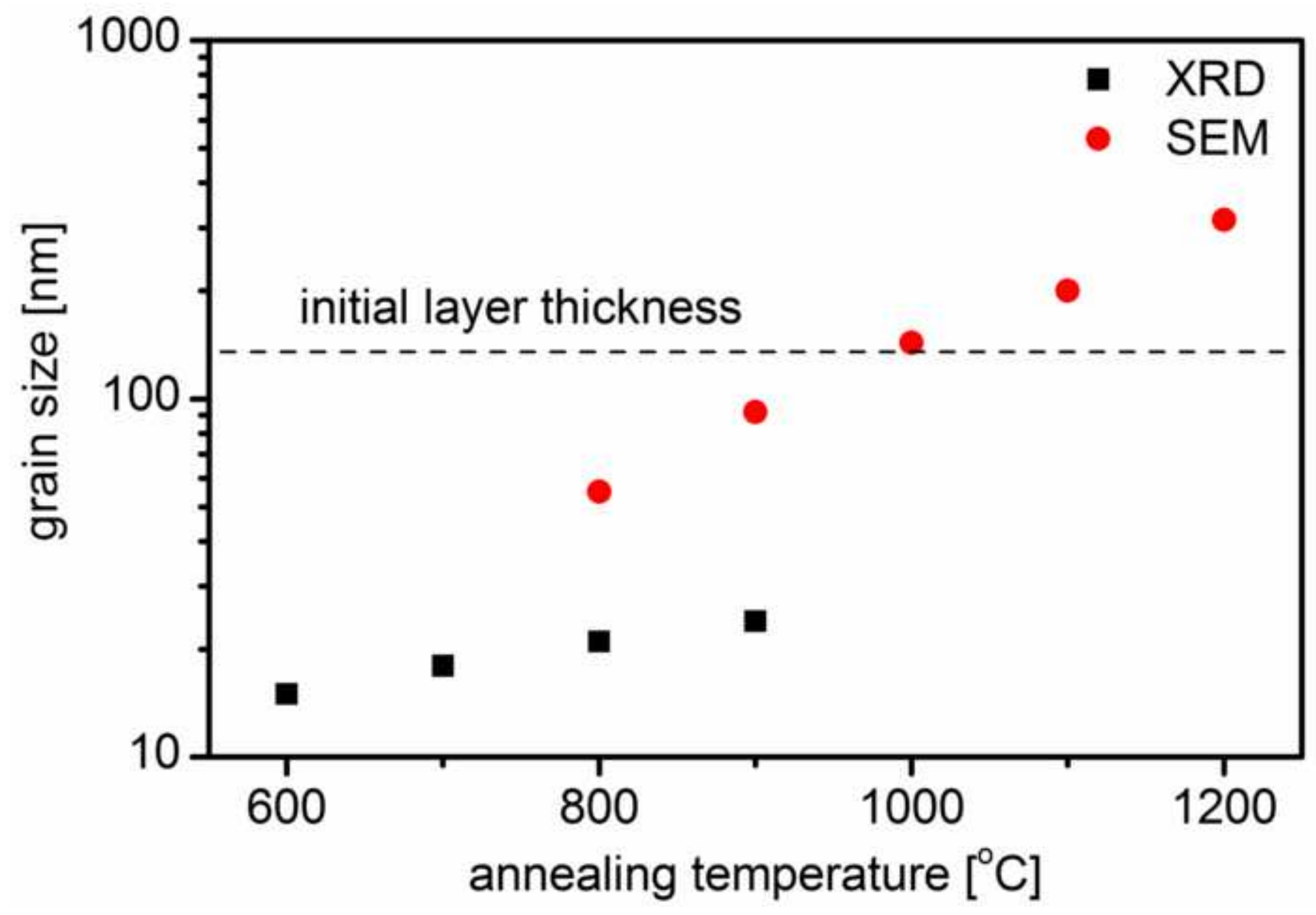




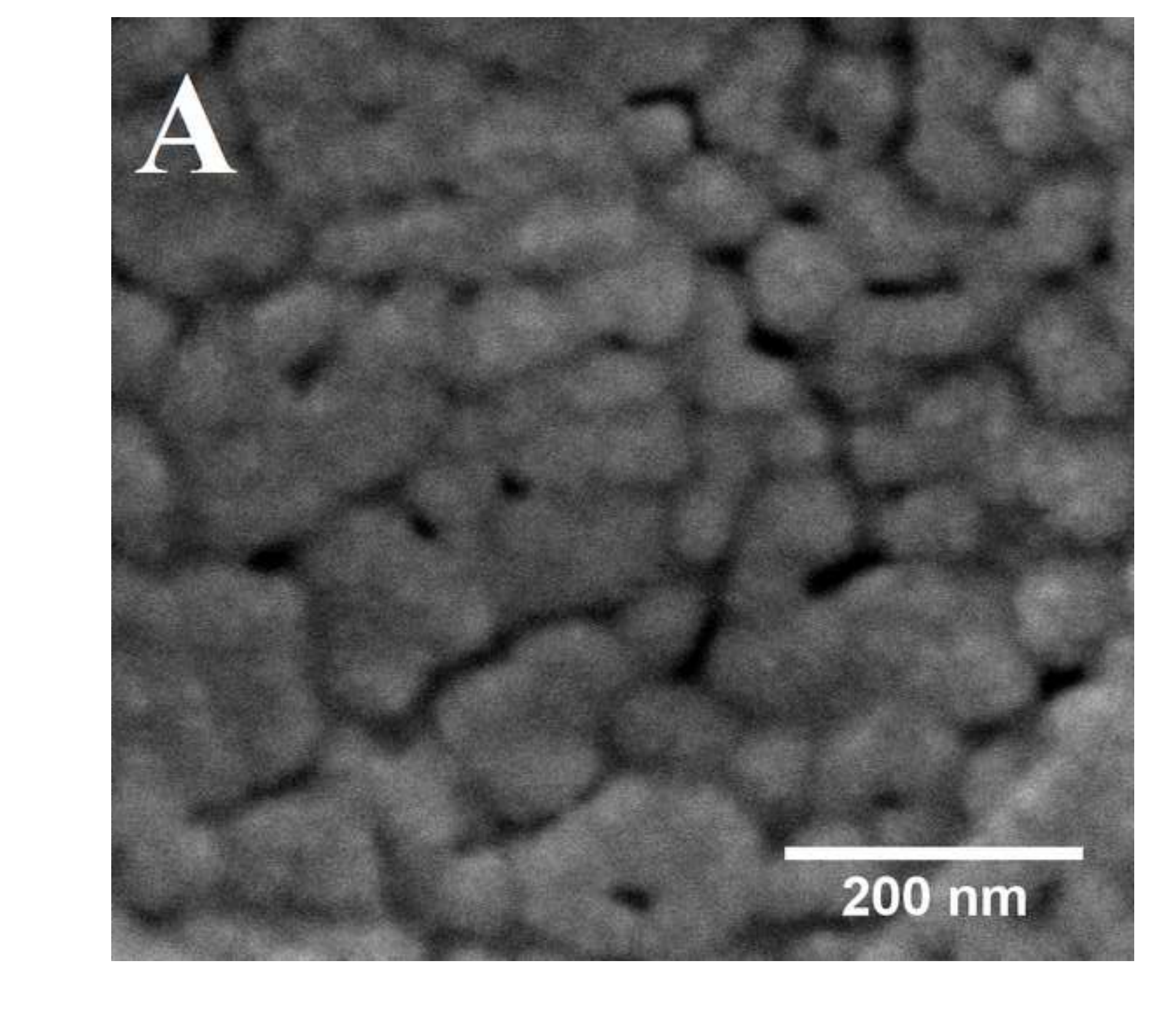

\title{
$200 \mathrm{~nm}$
}

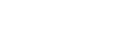

-

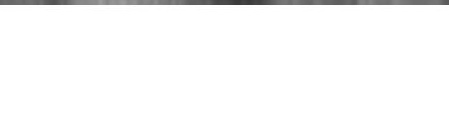

.
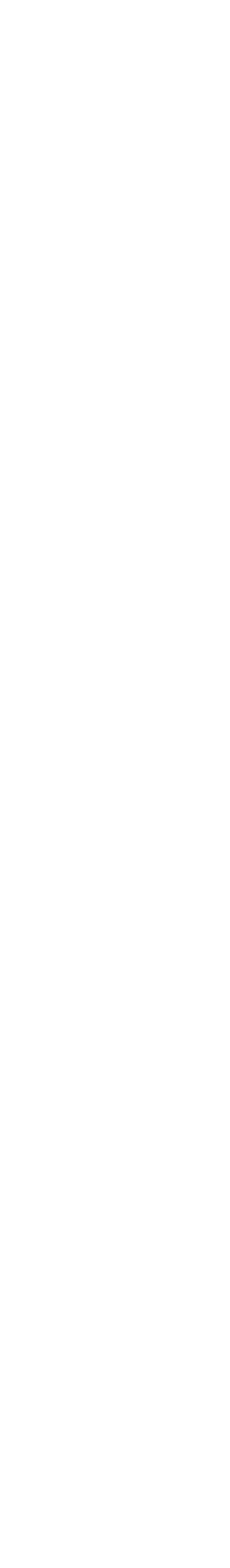
B

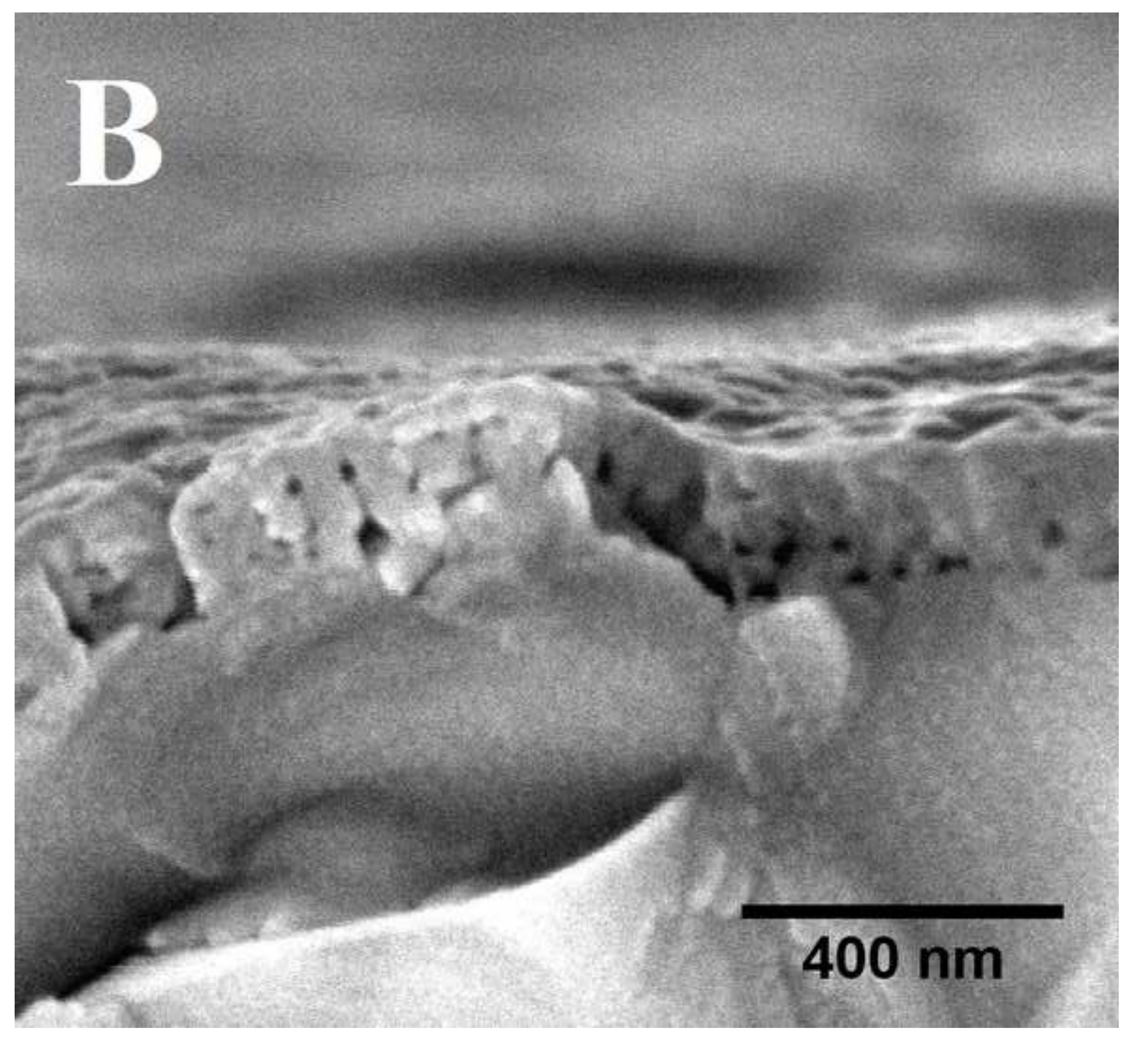

$400 \mathrm{~nm}$ $B$
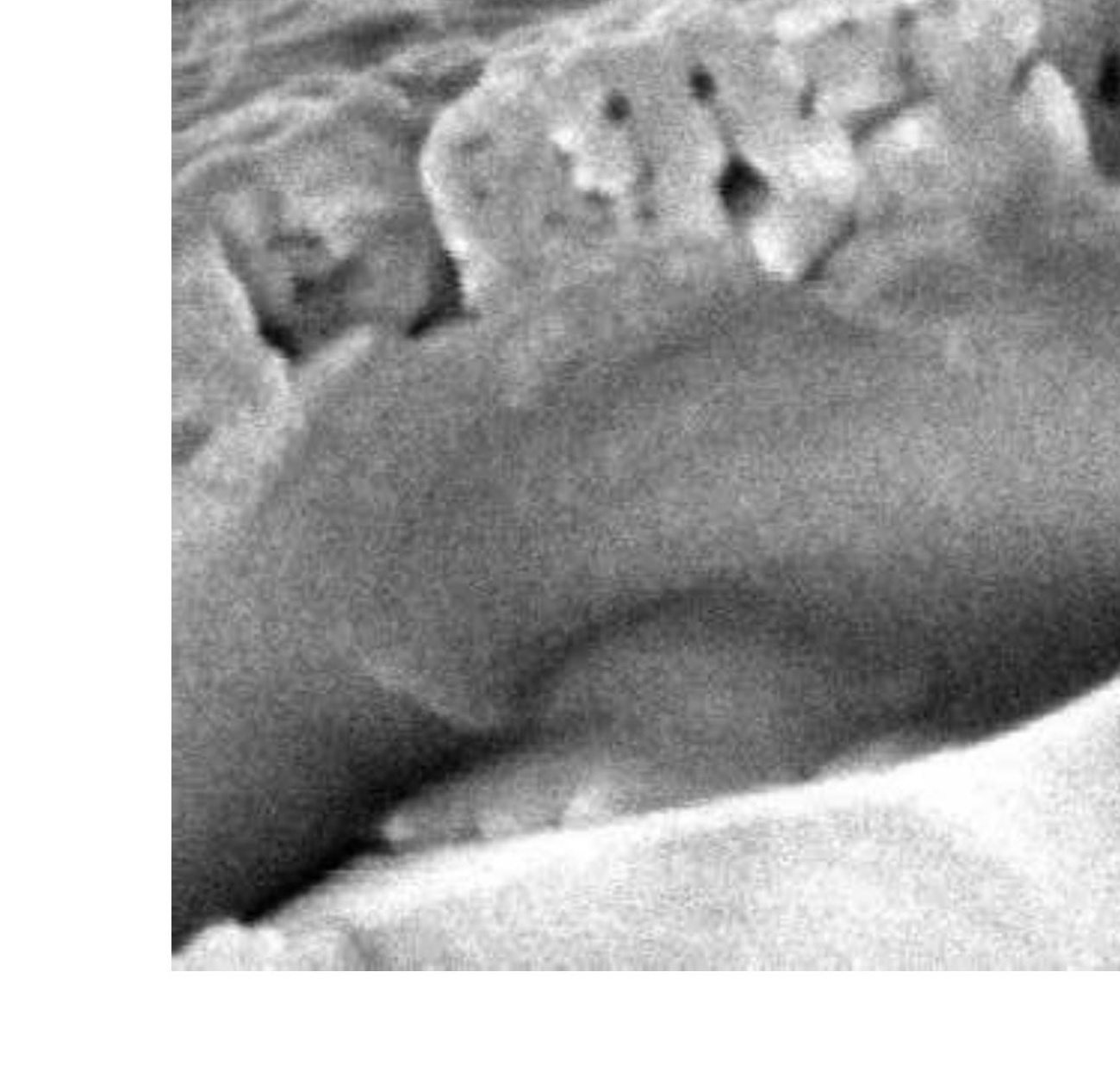


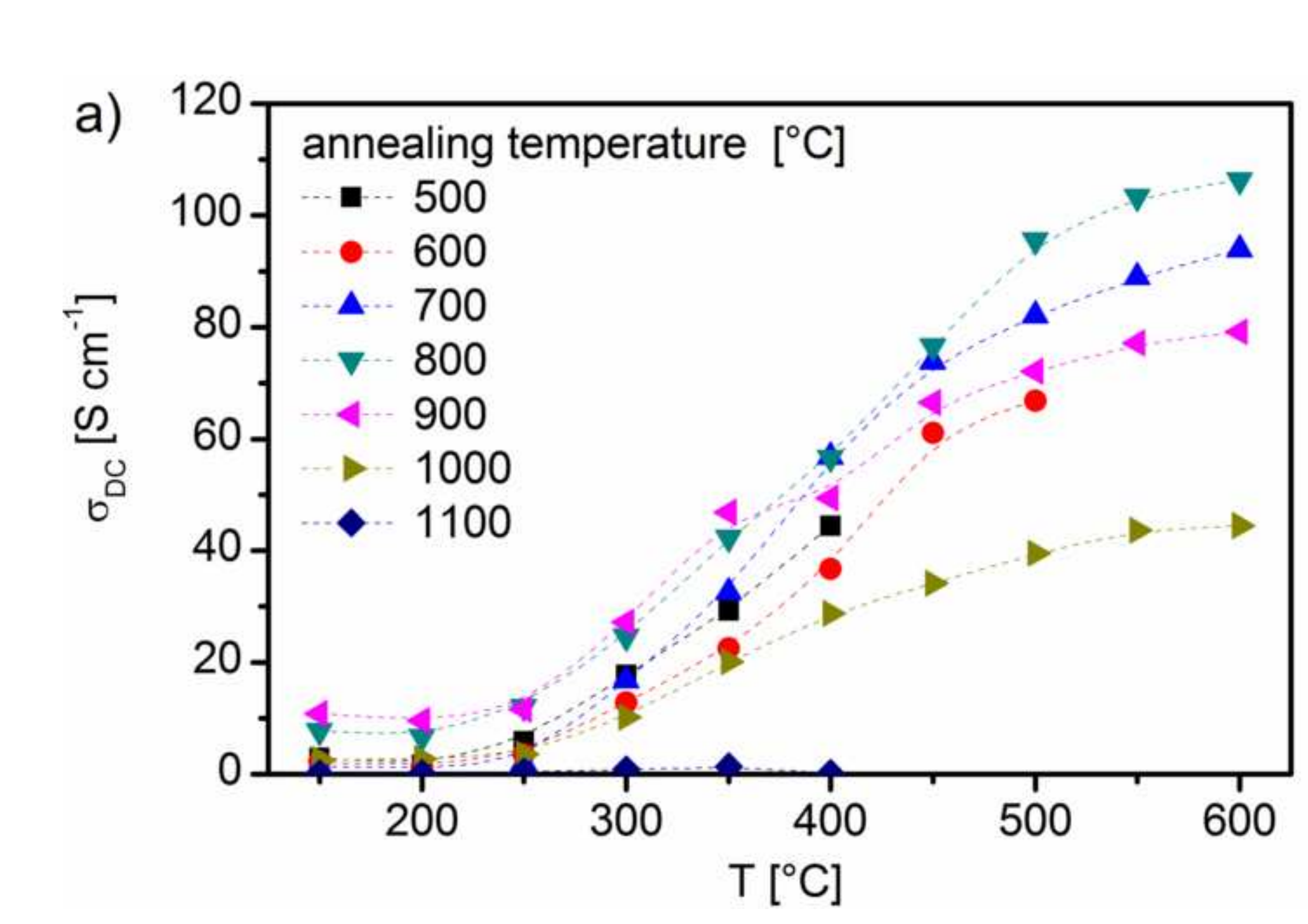




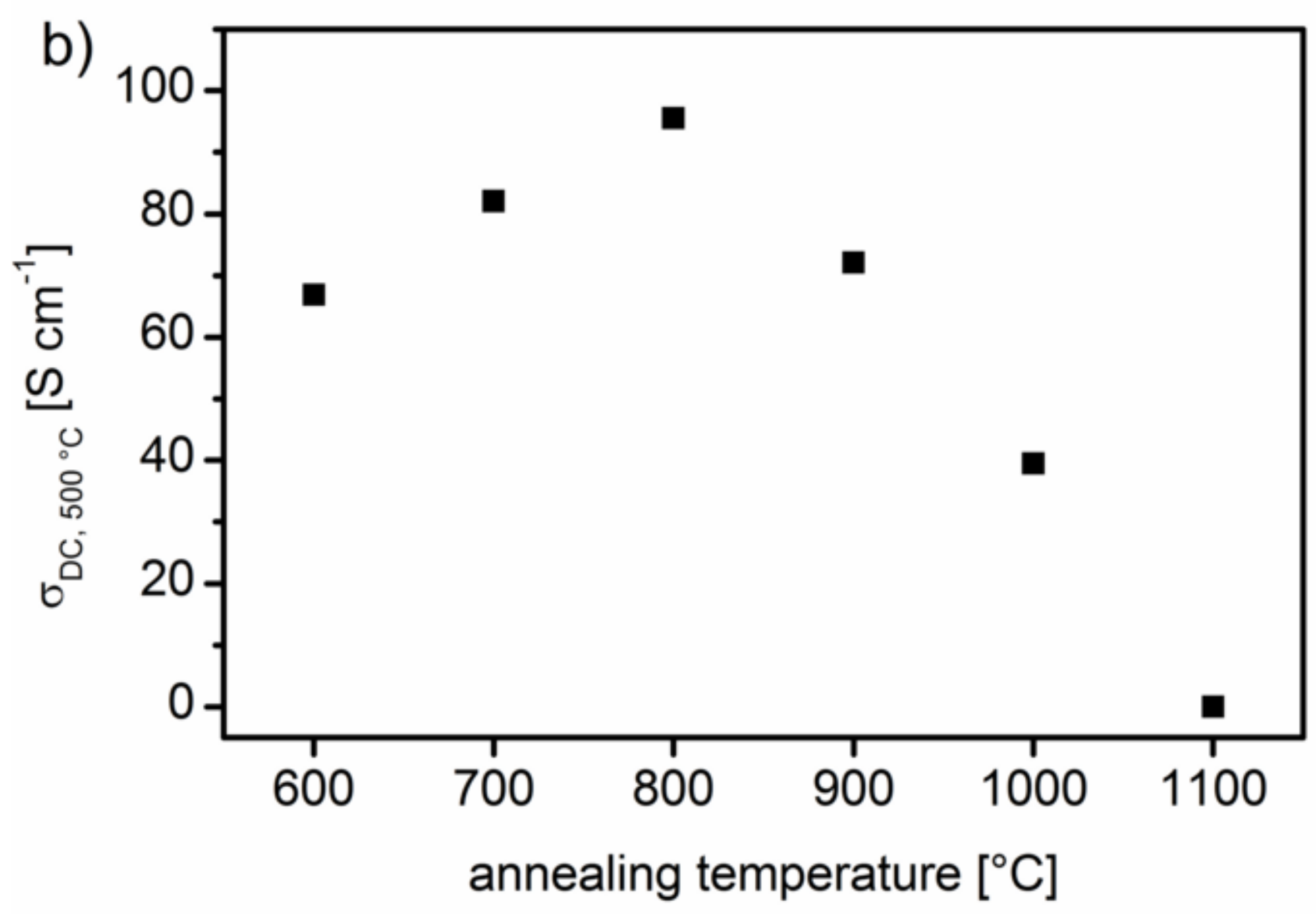




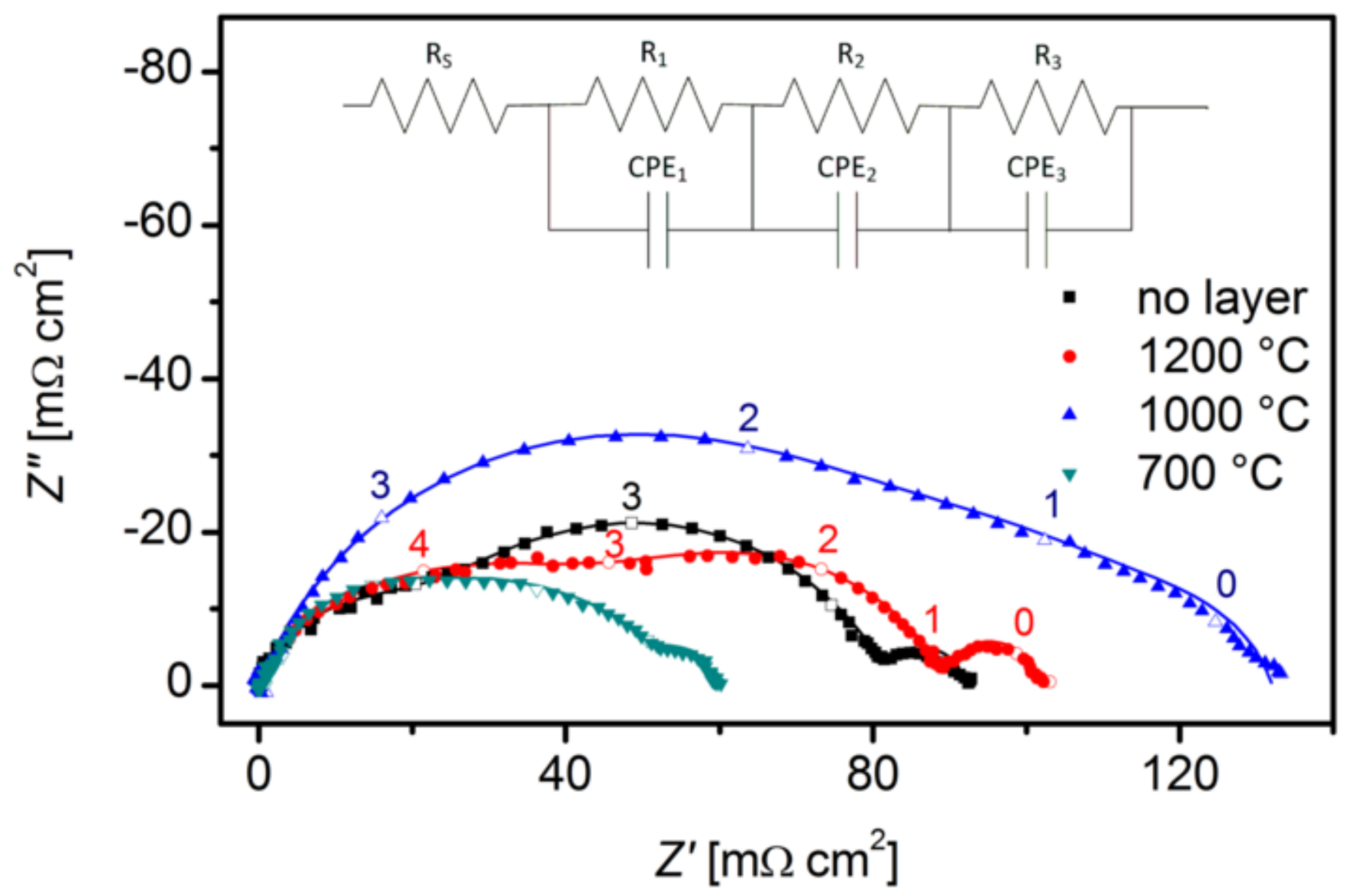




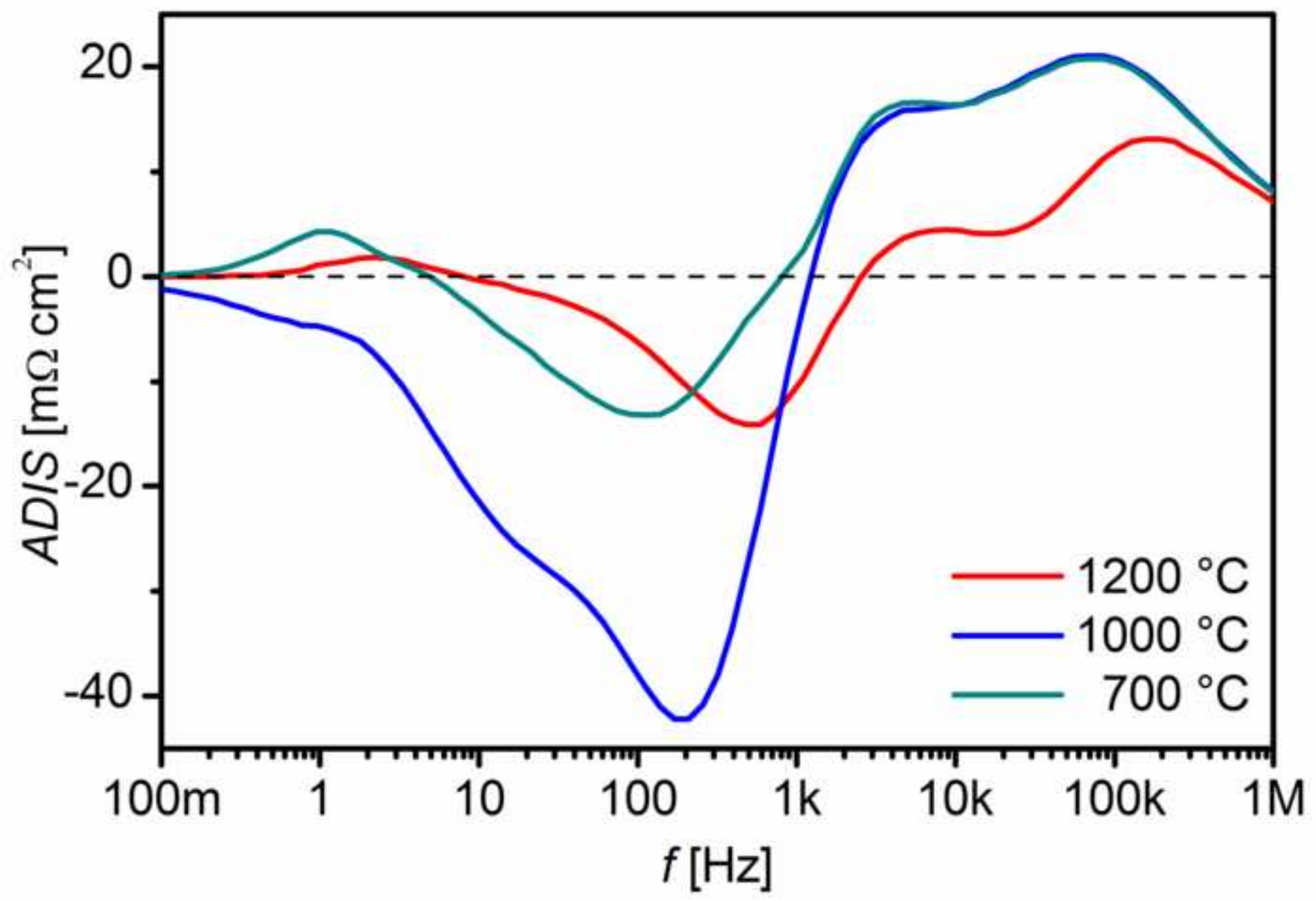




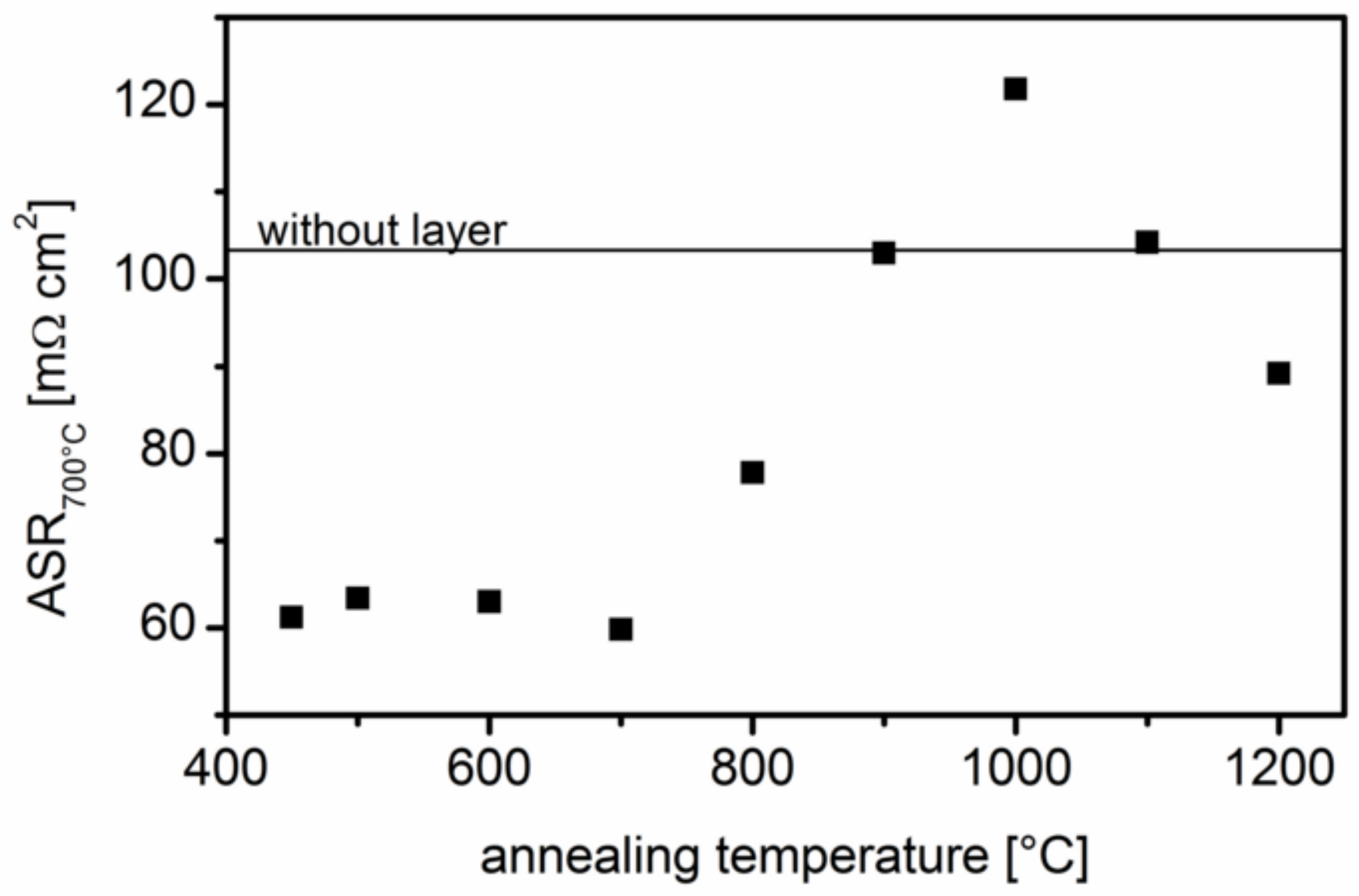




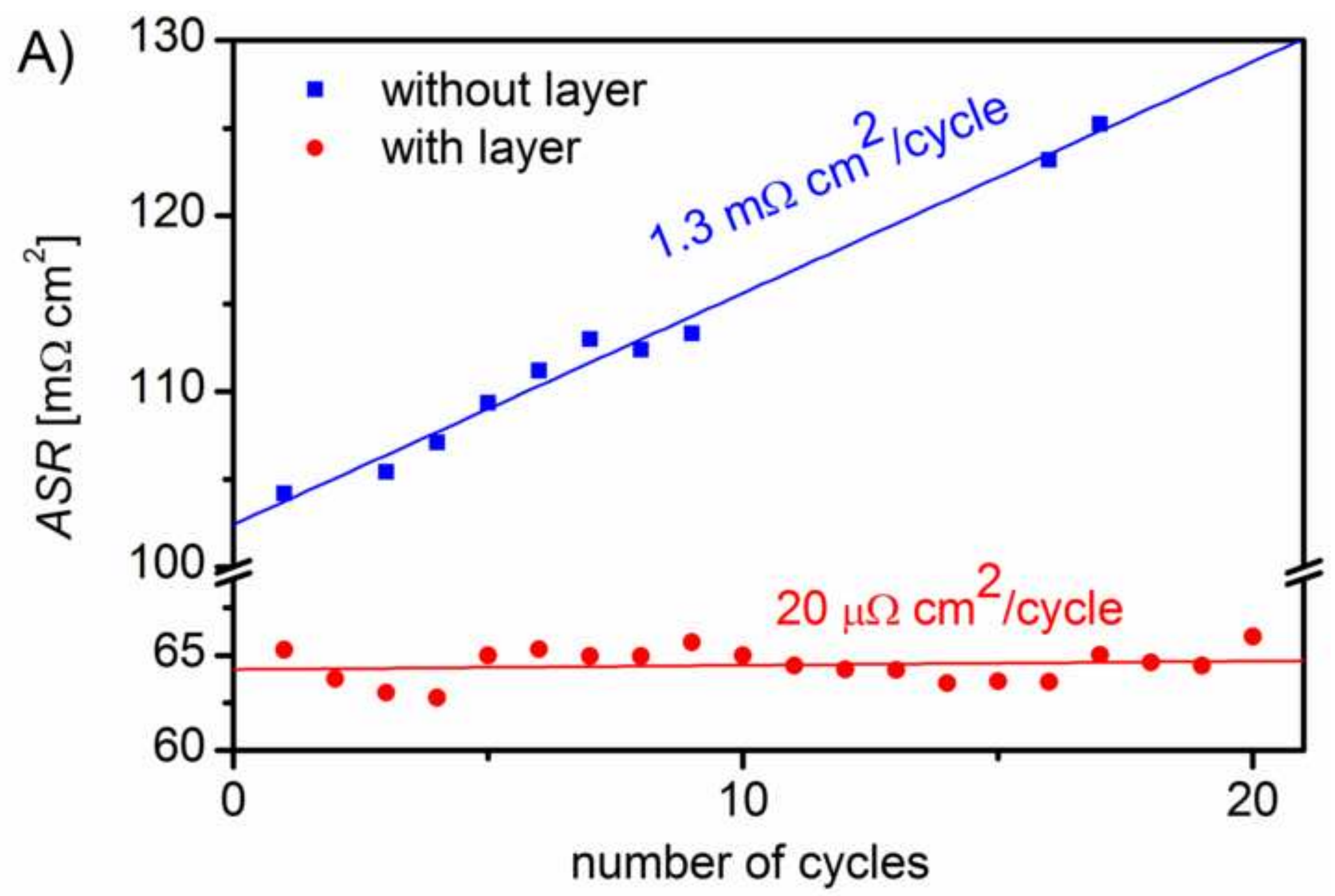




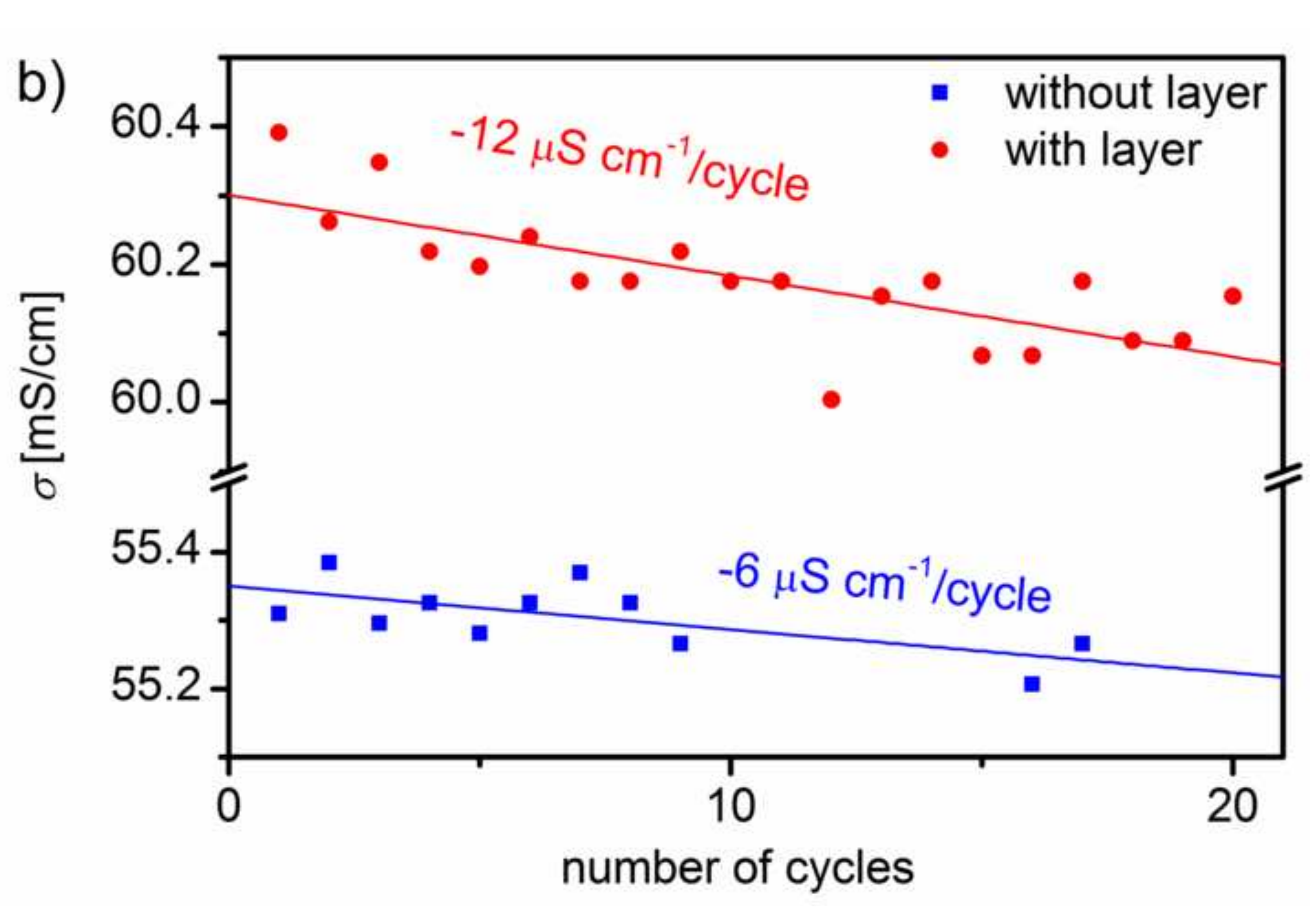




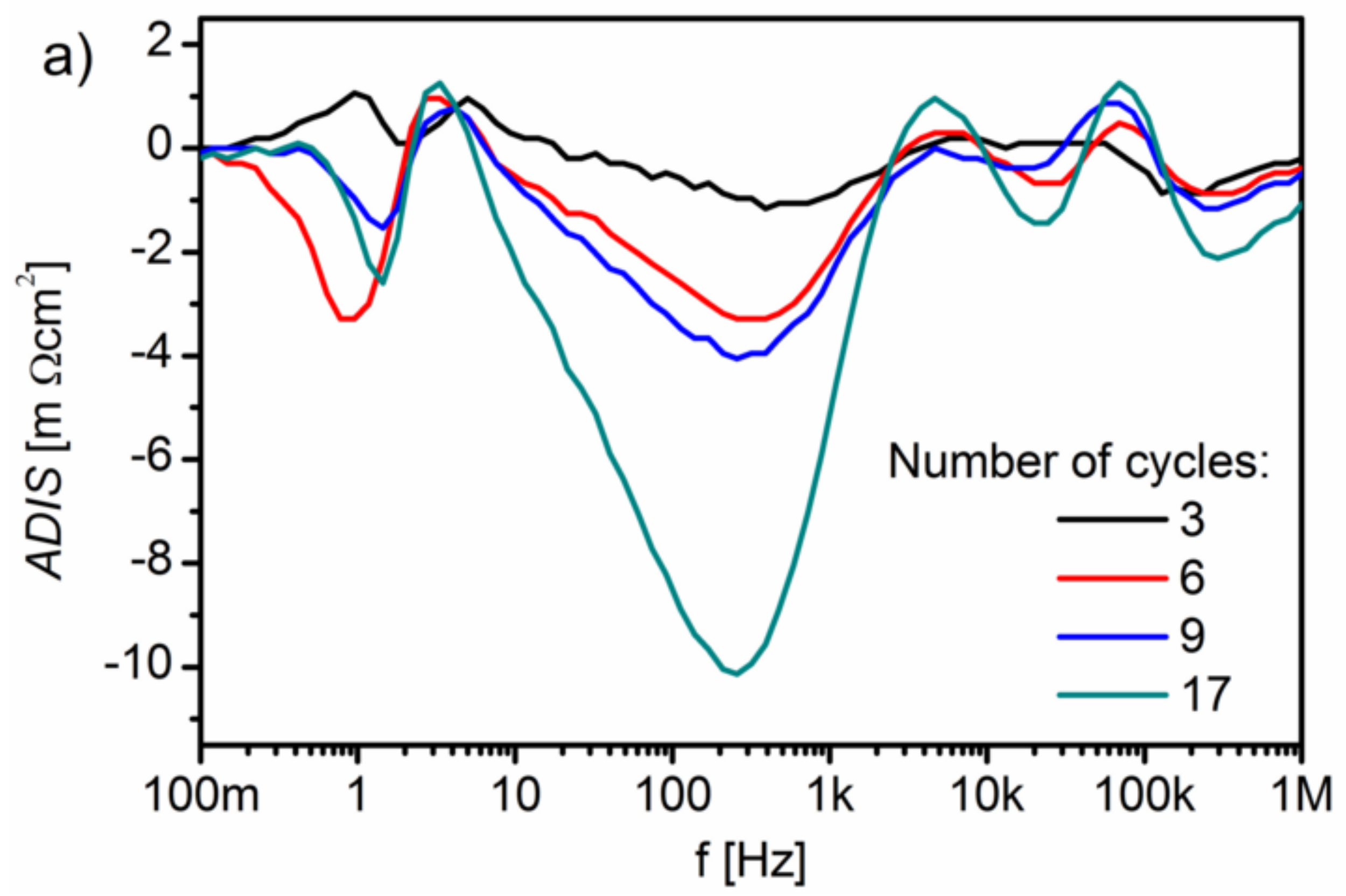




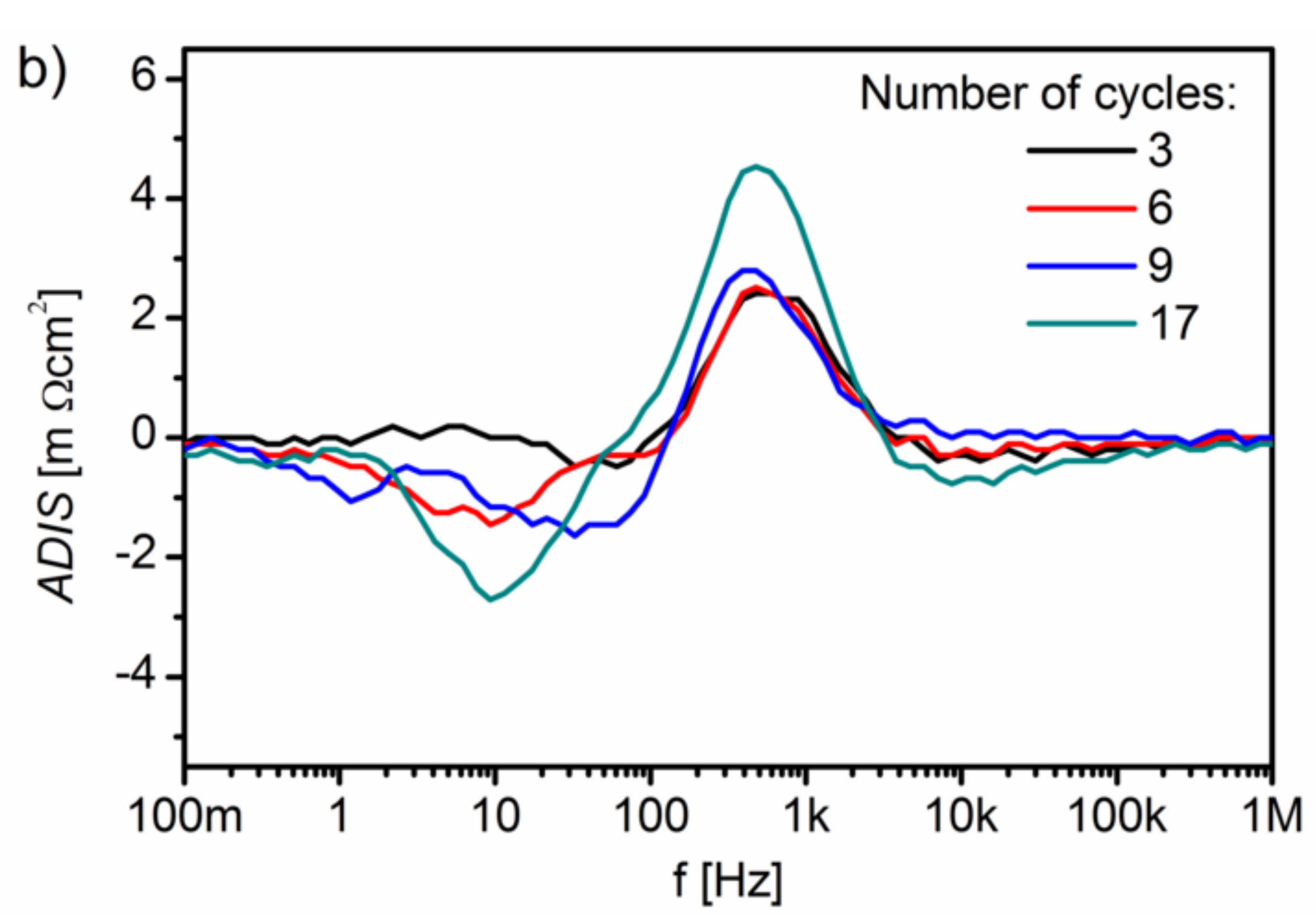

